EPJ Web of Conferences 21, 01004 (2012)

DOI: $10.1051 /$ epjconf/20122101004

(C) Owned by the authors, published by EDP Sciences, 2013

\title{
Note to: Neutron-induced cross sections of short-lived nuclei via the surrogate reaction method
}

G. Boutoux ${ }^{1}$, B. Jurado ${ }^{1}$, V. Méot ${ }^{2}$, O. Roig ${ }^{2}$, M. Aïche ${ }^{1}$, L. Mathieu ${ }^{1}$, G. Barreau ${ }^{1}$, N. Capellan ${ }^{1}$, I. Companis ${ }^{1}$, S. Czajkowski ${ }^{1}$, J.T. Burke ${ }^{3}$, E. Bauge ${ }^{2}$, J.M. Daugas ${ }^{2}$, T. Faul ${ }^{2}$, L. Gaudefroy ${ }^{2}$, P. Morel $^{2}$, N. Pillet ${ }^{2}$, P. Romain ${ }^{2}$, J. Taieb $^{2}$, C. Théroine ${ }^{2}$, X. Derkx ${ }^{4}$, O. Sérot ${ }^{5}$, I. Matea $^{6}$, L. Tassan-Got $^{6}$ and F. Gunsing ${ }^{7}$

${ }^{1}$ CENBG, CNRS/IN2P3, Université Bordeaux I, Chemin du Solarium, B.P. 120, 33175 Gradignan, France

2 CEA DAM DIF, 91297 Arpajon, France

${ }^{3}$ LLNL, Livermore, CA 94550, USA

${ }^{4}$ GANIL, 14076 CAEN, France

${ }^{5}$ CEA-Cadarache, DEN/DER/SPRC/LEPh, 13108 Saint Paul lez Durance, France

${ }^{6}$ IPN, CNRS/IN2P3, Univ. Paris-Sud, 91405 Orsay, France

${ }^{7}$ CEA Saclay, DSM/DAPNIA/SPhN, 91191 Gif-sur-Yvette cedex, France

Note to:

EPJ Web of Conferences 17, 06005 (2011), DOI: 10.1051/epjconf/20111706005,

EPJ Web of Conferences 21, 01002 (2012), DOI: 10.1051/epjconf/20122101002

Note that the article EPJ Web of Conferences 17, 06005 (2011) (DOI: 10.1051/epjconf/20111706005) was published in the proceedings of the " $5^{\text {th }}$ International Conference FUSION11" with preliminary results.

The article EPJ Web of Conferences 21, 01002 (2012) (DOI: 10.1051/epjconf/20122101002) was published in the proceedings of “CNR*11 - Third International Workshop on Compound Nuclear Reactions and Related Topics”, and provided final results and a more detailed interpretation concerning the angular-momentum distribution populated in the different surrogate reactions. 